\title{
Incidence and economic impact of ophthalmological occupational accidents in Greece
}

\author{
Kyriakos Souliotis ${ }^{1,4}$, Michalis Angelou ${ }^{2}$, Christina Golna ${ }^{3}$, Yannis Tountas $^{4}$ \\ ${ }^{1}$ Faculty of Social Sciences, University of Peloponnese, Corinth, Greece \\ ${ }^{2}$ Institute of Social Security, Athens, Greece \\ ${ }^{3} \mathrm{MSc}$ Health Regulation, Athens, Greece \\ ${ }^{4}$ Center for Health Services Research, Department of Hygiene and Epidemiology, Medical School, University of Athens, Athens, \\ Greece
}

Received 15 September 2009; revised 15 October 2009; accepted 16 October 2009

\begin{abstract}
Scope: This article seeks to assess the economic impact of industrial accidents with reference to the incidence of opthalmological industrial injuries occurring in the Thriacion Plain industrial zone in Greece during the period 1991-2000. Material and Methods: Data provided by 53 industrial units have been collected and classified. During the study period, 2,011 adults and juveniles out of the 15,600 people employed in the area (a 13\% aggregate) suffered opthalmological injuries occurring at the workplace. Results: The highest percentage of injuries were due to trauma (61\% of adults, $67 \%$ of juveniles), followed by chemical burns. In the majority of cases $(75 \%$ of adults and $50 \%$ of juveniles) treatment was provided at the local IKA (Social Security Fund) health care unit, in the town of Elefsis. It was estimated that a total of 10,192 working days were lost, with compensation costs (benefit payments) alone amounting to approximately $€ 118,000.00$, not allowing for indirect employer costs such as loss of productivity, substitution and replacement costs. Conclusions: The high incidence of industrial accidents in combination with the high percentage of child labor in the area of Thriacion Industrial Plain were striking and contributed significantly to higher rates of work-related injuries of ocular interest in Greece. The latter were shown to result in a significant deterioration of the employees' health status, with the majority of the accidents being due to the lack of safety precautions at the workplace at a considerable financial burden on the social security system in direct benefit payments. The social security system needs to press for tighter work safety regulations and their proper implementation if to minimize the burden these
\end{abstract}

accidents impose on its budget.

Keywords: Occupational Health; Cost of Care; Ophthalmological Accidents

\section{INTRODUCTION}

One of the primary objectives of the social security systems in most European countries is to cover for risks due to industrial injuries and occupational related diseases [1]. Over the past twenty years, changes in the manufacture and production process, largely aimed at an improvement of the work environment for employees, have led to the introduction of advanced technologies and the minimization of human interaction with high-risk machinery, in an effort to limit the extent of occupational / industrial accidents [2].

An occupational / industrial accident is "any violent, sudden and unforeseen incident occuring to the employee during or because of his work and resulting in a disability for work of a duration of more than 4 days" and, as such, manifests the effect of economic activity on the health of an employee [3], leading to a deterioration of the health status of the injured person, an increase in the social security burden of treatment and rehabilitation, abseintism, decrease in productivity and lost revenue [4].

Whereas improvements in working conditions in Greece from 1970 onwards resulted in a decrease in the incidence of industrial accidents, and especially fatal ones, related morbidity remained relatively high until 1989 . During the next decate, morbidity decreased substantially $[5,6]$. Industrial accidents in Greece were largely related to the low level of work safety standards, the unsuitability of the work environment, the lack of sufficient measures to monitor safety regulations and collect and analyze relevant information, the recruitment of non-specialized workers for specialized tasks and the lack of state control over enterprises, particularly in monitoring compliance with safety regulations [7]. 
Table 1. Work accidents to IKA insured employees and consequences (1991-1995).

\begin{tabular}{|c|c|c|c|c|c|}
\hline Accidents -consequences & 1991 & 1992 & 1993 & 1994 & 1995 \\
\hline Death & 222 & 227 & 240 & 229 & 206 \\
\hline $\begin{array}{l}\text { Absence from work and } \\
\text { compensation }\end{array}$ & 25,611 & 25,582 & 24,524 & 23,231 & 21,946 \\
\hline $\begin{array}{l}\text { Temporary disability and } \\
\text { retirement }\end{array}$ & 673 & 474 & 504 & 507 & 392 \\
\hline $\begin{array}{l}\text { Permanent disability and } \\
\text { retirement }\end{array}$ & 290 & 300 & 311 & 317 & 253 \\
\hline $\begin{array}{l}\text { Minor injury with no impact } \\
\text { on ability to perform tasks }\end{array}$ & 74 & 84 & 75 & 78 & 145 \\
\hline Total work accidents & 26,870 & 26,667 & 25,654 & 24,362 & 22,942 \\
\hline
\end{tabular}

Table 2. Subsidies paid due to industrial accidents to IKA insureds, 1995.

\begin{tabular}{ll}
\hline Benefit data & Total \\
\hline Cases & 22 \\
Days of subsidy & 689 \\
Bonus days & 52 \\
Total days & 741 \\
Cost in euros & $8,516,327.77$ \\
Cost per case & 395.37 \\
Days per case & 34 \\
Source: Social Security Institute, Statistical Report 1996, Athens. & \\
\hline
\end{tabular}

In $1995,0.90 \%$ of accidents at the workplace resulted in death, 95.66\% resulted in absence from work and payment of compensation, $1.71 \%$ resulted in temporary disability, $1.10 \%$ resulted in permanent disability and $0.63 \%$ related to minor injury that did not hinder the employee from performing his duties (Table 1).

In the same year, IKA, the largest social security fund, where $55 \%$ of the population are insured (compulsory health / social insurance), paid out $€ 8.5$ million in compensation (benefits) for 21,540 industrial accidents [8]. Compensation covered an average of 34 days per incident with the per capita benefit amounting to $€ 395$ (Table 2).

It should be noted that this figure did not include benefits in kind for treatment, which were paid separately to the insureds, or the cost of health services actually provided at the IKA local health units or hospitals. Nonetheless, in 1996, this compensation in kind for industrial accidents amounted to $6 \%$ of IKA's total provision for illness in money terms [8], which is considered high especially as it is an "avoidable" cost that could potentially lead to catastrophic health care expenditure for the security fund, the employee and the employer.

In the remit of industrial accidents, work related injuries of ophthalmologic interest have been in the center of recent scientific analysis and debate [9-11]. While ocular injuries appear to be relatively higher in industrial settings at some countries, such as Southeastern Nigeria, where $12.5 \%$ of industrial accidents affected the eye [9], comparably high incidence rates are also observed in the agricultural sector in both USA and Italy [10,11].

In the view of 1) the growing importance of ocular accidents occurring at the workplace and 2) the significant economic burden imposed on the social security system by occupational accidents in Greece, this paper assesses the economic impact of ocular injuries at the workplace in one of the most industrialised areas of the country.

\section{METHODS}

This paper analyses the incidence and the economic consequences of ophthalmological industrial accidents in the Thriasion Plain industrial zone in Greece over the period 1991-2000. Data were collected from fifty three (53) industries that operate in the greater area of the Thriacion Plain and employee health records at the primary health care clinic of the IKA local health unit in Elefsis. Cost data were obtained from the Annual IKA Statistical Bulletin. The cost of the accidents was estimated in monetary terms both for the social security system and the individuals (injured employees and employers) alike. 
Table 3. Employees per category/sex and opthalmological accidents in the industrial area of Thriacion Plain (1991-2000).

\begin{tabular}{|c|c|c|c|c|}
\hline \multicolumn{2}{|c|}{ EMPLOYEES } & \multicolumn{3}{|c|}{ ACCIDENTS } \\
\hline Adults & & Cases & $\begin{array}{c}\% \text { (compared to the total } \\
\text { of accidents) }\end{array}$ & $\begin{array}{c}\text { Employees per acci- } \\
\text { dent }\end{array}$ \\
\hline MEN & 8,150 & 1,785 & $89 \%$ & 8.12 \\
\hline$\%$ (compared to the adults total) & 56.21 & & & \\
\hline WOMEN & 6,350 & & & \\
\hline$\%$ (compared to the adults total) & 43.79 & & & \\
\hline TOTAL & 14,500 & & & \\
\hline$\%$ (compared to the total of employees) & 92.95 & & & \\
\hline \multicolumn{5}{|l|}{ Juveniles } \\
\hline MEN & 995 & 226 & $11 \%$ & 4.87 \\
\hline$\%$ (compared to the juvenile total) & 90.45 & & & \\
\hline WOMEN & 105 & & & \\
\hline$\%$ (compared to the juvenile total) & 9.55 & & & \\
\hline TOTAL & 1,100 & & & \\
\hline$\%$ (compared to the total of employees) & 7.05 & & & \\
\hline All Employees & 15,600 & 2,011 & $100 \%$ & 7.76 \\
\hline
\end{tabular}

Table 4. Work opthalmological accidents in adults and juvenile in the industrial area of Thriacion Plain (1991-2000).

\begin{tabular}{cccccc}
\hline Year & Adult Accidents & $\mathbf{\%}$ & Juvenile Accidents & \% & Total of accidents \\
\hline 1991 & 228 & 86.36 & 36 & 13.64 & 264 \\
1992 & 114 & 83.82 & 22 & 16.18 & 136 \\
1993 & 78 & 85.71 & 13 & 14.29 & 91 \\
1994 & 76 & 84.44 & 14 & 15.56 & 90 \\
1995 & 68 & 94.44 & 4 & 5.56 & 72 \\
1996 & 116 & 95.87 & 5.13 & 121 \\
1997 & 149 & 94.90 & 27 & 5.10 & 157 \\
1998 & 234 & 89.66 & 50 & 10.34 & 261 \\
1999 & 366 & 87.98 & 47 & 12.02 & 416 \\
2000 & 356 & 88.34 & 226 & 11.24 & 403 \\
TOTAL & 1,785 & 88.76 & & & 2,011 \\
\hline
\end{tabular}

\section{RESULTS}

A total of 15,600 workers were employed in the area over the study period, of whom 14,500 were adults and 1,100 juveniles. Of them, an aggregate $13 \%$ (1,785 adults and 226 juveniles) suffered ocular casualties over the study period (Table 3). This percentage is a striking 4.5 times higher than the average representation of ocular injuries in the overall industrial accidents ( $2.8 \%$ of total accidents) reported by IKA for that period.

The number of opthalmological injuries sustained by both adults and juveniles varied significantly between 1991-1996 and 1996-2000. Table 4 depicts a 70\% decline in opthalmological industrial accidents (from 228 to 68 ) for adults and an $88 \%$ decline (from 36 to 4 ) for juvenile workers between 1991 and 1996. Conversely, over the period 1996-2000, there was a marked increase of 206\% (from 116 to 356) in adult ophthalmological industrial accidents and $840 \%$ (from 5 to 47 ) in juvenile ones, despite the introduction of additional European Union legislation on tighter safety controls in the workplace (6 new legislative acts over the study period).

A large proportion of the employees seeking treatment for ophthalmological industrial injuries had not been legally employed and were uninsured, with the rate of child labor in the area being quite significant (7.05\%). Children displayed a greater propensity towards accidents at the workplace (a chance of 1 in 4.87 for juveniles as 
Table 5. Adult work accidents by eye anatomical area subjected to injury (1991-2000).

\begin{tabular}{ccccccccccc}
\hline Eye anatomical area & $\mathbf{1 9 9 1}$ & $\mathbf{1 9 9 2}$ & $\mathbf{1 9 9 3}$ & $\mathbf{1 9 9 4}$ & $\mathbf{1 9 9 5}$ & $\mathbf{1 9 9 6}$ & $\mathbf{1 9 9 7}$ & $\mathbf{1 9 9 8}$ & $\mathbf{1 9 9 9}$ & $\mathbf{2 0 0 0}$ \\
\hline Eyelids & 65 & 40 & 20 & 25 & 20 & 25 & 21 & 48 & 100 & 90 \\
Conjunctivae & 25 & 4 & 8 & 15 & 7 & 5 & 25 & 40 & 43 & 20 \\
Cornea & 110 & 70 & 46 & 30 & 41 & 63 & 79 & 134 & 209 & 219 \\
Sclera & 17 & & 4 & 6 & & 16 & 14 & 10 & 11 & 20 \\
Iris & 7 & & & & & 2 & 5 & & 2 & 4 \\
Lens & 2 & & & & & 5 & 5 & 2 & 1 & 3 \\
Hyaloid & 2 & & & & & & & & \\
\hline
\end{tabular}

Table 6. Juvenile work accidents by eye anatomical area subjected to injury (1991-2000).

\begin{tabular}{ccccccccccc}
\hline Eye anatomical area & $\mathbf{1 9 9 1}$ & $\mathbf{1 9 9 2}$ & $\mathbf{1 9 9 3}$ & $\mathbf{1 9 9 4}$ & $\mathbf{1 9 9 5}$ & $\mathbf{1 9 9 6}$ & $\mathbf{1 9 9 7}$ & $\mathbf{1 9 9 8}$ & $\mathbf{1 9 9 9}$ & $\mathbf{2 0 0 0}$ \\
\hline Eyelids & 13 & 11 & 4 & 7 & 2 & 5 & 6 & 20 & 30 & 31 \\
Conjuctivae & 10 & 2 & 8 & 5 & 2 & & 2 & 5 & 3 & 7 \\
Cornea & 2 & 4 & 1 & 1 & & & & 2 & 5 & 9 \\
Sclera & 9 & 5 & & 1 & & & & & \\
Iris & 1 & & & & & & & & & \\
Lens & 1 & & & & & & & & \\
Hyaloid & & & & & & & &
\end{tabular}

Table 7. Cost estimation surcharged to IKA by absence reimbursement due to adult industrial opthalmological accidents in the Thriacion Plain (1991- 2000).

\begin{tabular}{ccccccccc}
\hline $\begin{array}{c}\text { Anatomical } \\
\text { area }\end{array}$ & Incidents & $\begin{array}{c}\text { Average } \\
\text { recovery } \\
\text { period }\end{array}$ & $\begin{array}{c}\text { Total days } \\
\text { of recovery }\end{array}$ & $\begin{array}{c}\text { Days paid } \\
\text { by em- } \\
\text { ployer }\end{array}$ & $\begin{array}{c}\text { Days paid } \\
\text { by IKA }\end{array}$ & $\begin{array}{c}\text { Employer } \\
\text { cost }\end{array}$ & $\begin{array}{c}\text { Total re- } \\
\text { IKA cost }\end{array}$ & $\begin{array}{c}\text { imburse- } \\
\text { ment cost }\end{array}$ \\
Eyelids & 454 & 4 & 1,816 & 1,362 & 454 & $15,836.37$ & $5,278.79$ & $21,115, .16$ \\
Conjuctivae & 192 & 4 & 768 & 576 & 192 & $6,697.32$ & $2,232.44$ & $8,929.76$ \\
Cornea & 1,001 & 3 & 3,003 & 3,003 & 0 & $34,916.76$ & 0.00 & $34,916.76$ \\
Sclera & 98 & 23 & 2,254 & 294 & 1,960 & $3,418.42$ & $22,789.49$ & $26,207.92$ \\
Iris & 20 & 23 & 460 & 60 & 400 & 697.64 & $4,650.92$ & $5,348.55$ \\
Lense & 18 & 23 & 414 & 54 & 360 & 627.87 & $4,185.83$ & $4,813.70$ \\
Hyaloid & 2 & 23 & 46 & 6 & 40 & 69.76 & 465.09 & 534.86 \\
TOTAL & $\mathbf{1 , 7 8 5}$ & & $\mathbf{8 , 7 6 1}$ & $\mathbf{5 , 3 5 5}$ & $\mathbf{3 , 4 0 6}$ & $\mathbf{6 2 , 2 6 4 . 1 5}$ & $\mathbf{3 9 , 6 0 2 . 5 6}$ & $\mathbf{1 0 1 , 8 6 6 . 7 1}$ \\
\hline
\end{tabular}

Table 8. Cost estimation surcharged to IKA by absence reimbursement due to juvenile employees work opthalmological accidents in the Thriacion Plain (1991-2000).

\begin{tabular}{ccccccccc}
\hline $\begin{array}{c}\text { Anatomical } \\
\text { area }\end{array}$ & Incidents & $\begin{array}{c}\text { Average } \\
\text { recovery } \\
\text { period }\end{array}$ & $\begin{array}{c}\text { Total days of } \\
\text { recovery }\end{array}$ & $\begin{array}{c}\text { Days paid } \\
\text { by em- } \\
\text { ployer }\end{array}$ & $\begin{array}{c}\text { Days } \\
\text { paid by } \\
\text { IKA }\end{array}$ & $\begin{array}{c}\text { Employer } \\
\text { cost }\end{array}$ & $\begin{array}{c}\text { IKA cost } \\
\text { Total reim- } \\
\text { bursement cost }\end{array}$ \\
\hline $\begin{array}{c}\text { Eyelids } \\
\text { Conjuctivae }\end{array}$ & 129 & 4 & 516 & 387 & 129 & $4,499.76$ & $1,499.92$ & $5,999.68$ \\
Cornea & 44 & 4 & 176 & 132 & 44 & $1,534.80$ & 511.60 & $2,046.40$ \\
Sclera & 24 & 3 & 72 & 72 & 0 & 837.17 & 0.00 & 837.17 \\
Iris & 22 & 23 & 506 & 66 & 440 & 767.40 & $5,116.01$ & $5,883.41$ \\
Lense & 2 & 23 & 115 & 15 & 100 & 174.41 & $1,162.73$ & $1,337.14$ \\
TOTAL & $\mathbf{2 2 6}$ & 23 & 46 & 6 & 40 & 69.76 & 465.09 & 534.86 \\
\hline
\end{tabular}


compared to 1 in 8.12 for adults). This uninsured population (including illegally employed children) did not generate revenue (compulsory insurance fees) for the social security fund but, nonetheless, sought and received treatment for their accidents at the IKA local health care unit, at a considerable, additional and unaccounted for, cost for the fund.

Tables 5 and $\mathbf{6}$ depict the steady increase in injuries involving the eyelids both for adults and juveniles, especially after 1998, and the cornea (especially in adults), while injuries involving the conjunctivae have also displayed a relative increase. Eye injury was most commonly caused by metal chips, cement dust, fragments of wood, pieces of coal stone and arc rays, all of which could be prevented by wearing appropriate protective eye coverings. Mechanical injuries accounted for 1,076 of adult injuries $(60.3 \%)$, chemical burns for 630 (35.3\%) and clashes for 79 (4.4\%). Injury causes in juveniles were distributed similarly, though no injuries were attributed to clashes.

Seventy-five percent of the adults thus injured were treated at the local health unit of IKA in Elefsis, whereas the remainder was transported to the opthalmological Clinics of Athens and Piraeus (National Health System NHS-Clinics). Of the juveniles injured, 50\% were treated at the local health unit and the others were transported to the two Children's Hospitals in Athens (NHS Hospitals) $[12,13]$. It should be noted that according to the Greek NHS principles, it is compulsory that treatment is provided to everyone in need, irrespective of insurance status. In this light, even if uninsured or illegally employed, all employees that suffered ocular industrial accidents received treatment either at a cost that fell on the social security fund or directly the NHS (the hospital budget).

IKA, which insures the majority of employees in the area, apart from covering treatment expenses, pays out compensation, sick-leave subsidies and a disability pension for either permanent or temporary disability. Based on the average compensation per day of absence from work, the cost to IKA for each employee amounts to:

IKA cost $=$ Days of absence -3 (paid by the employer) $\mathrm{x}$ average daily compensation

Whereas days of leave are estimated using the formula: type of injury $\mathrm{x}$ factor $\mathrm{n}$ (which expresses the days required for recovery for each category of injury).

Thus, the cost to social security (IKA) in 1995 prices for the coverage of opthalmological injuries occurring in the Thriacion Plain industrial zone in 1995 wages amounted to $€ 39,602.56$ for adults (Table 7) and $€ 8,755.35$ for juveniles (Table 8), at a total burden of injury of $€$ $48,357.91$. The above estimation is based on an average daily compensation multiplied by the days required until recovery; the days required for recovery are on average 4 (3-5) for injuries to the eyelids and conjuctivae, 3 (2-4) for injuries to the cornea and 23 (5-30) for injuries sustained to sclerae, iris, lens and vitreous.
The burden of disease on employees amounted to approximately $€ 62,264.15$ for adults and $€ 7,883.30$ for juveniles, at a total of $€ 70,144.46$. Overall, the total cost of opthalmological industrial accidents in the Thriacion Plain industrial zone during the 1990s was estimated at $€$ $118,505.36$. It should be noted that this was the cost incurred for sick leave only and, thus, an underestimate of the full economic burden of disease, as it does not allow for indirect employer costs such as replacement costs, productivity losses, delays in order processing or invoicing and adverse publicity.

As mentioned before, compensation costs paid out by the social security did not include the provision of services or payments in kind for treatment of the insured, which were exponientially higher than the compensation cost. Given the lack of published hospital and IKA treatment data [14], this cost could not be estimated in a credible manner. Compensation costs are thus used in this paper as an indicator of the extent of preventable and avoidable expense to the social security system (and to the NHS) that stricter implementation of work safety regulations could result to.

\section{DISCUSSIONS}

Data analysed in this paper show that the conditions existing in the Thriacion Plain industrial zone favor the occurrence of opthalmological industrial accidents, due to the lack of implementation of strict safety regulations, lack of information, ignorance of risks (resulting to carelessness), difficult working conditions, diminished perception, inexperience and insufficient physical strength. The probability of an accident occurring is further aggravated by the high rate of child labor that is essentially more vulnerable to such accidents.

These accidents, that to a great extent could be prevented through the use of protective eye coverings and more appropriate safety regulations, effect a high health and economic burden on social security, the employee and the employer alike and can ultimately lead to unemployment in an area where the primary source of income is from employment in the industrial sector [12-13]. It is recommended that in accordance with European guidelines on health and safety at work [15], legislation addressing the use of protective devices in high-risk industries should be vigorously enforced and compliance better monitored. This would not only improve the eye health of industrial workers in Greece but, most crucially, prevent avoidable expense to the fragile social security system and the NHS, which face major economic constraints on their budgets.

\section{REFERENCES}

[1] W. Hacker, R. Rosenbrock, J. Siegrist, (1996) Health pro- 
motion in the work environment-old and new challenges for public health. Gesundheitswesen, 58(2), 152-4.

[2] T. N. Herington, (1995) Occupational injuries: Evaluation, management and prevention. Mosby Publications.

[3] S. Soulis, (1998) Special issues of medical and social policy. Notes, Technological Educational Institute of Athens, Athens, Greece.

[4] I. Sari-Minodier and A. Botta, (1998) Insutrial accidents and occupatuinal diseases. Definition, Rev Prat, 48(7), 777-80.

[5] A. Linou, (1996) The epidemiology and prevention of occupational diseases. Monograph. Univ. of Athens, Athens, Greece.

[6] (1994) National statistical service of greece, statistical year book of Greece (series 1970-91). Athens, Greece.

[7] A. Terpos, (1998) Study of information systems in the sector of occupational health and safety. Hellenic Institute of Health and Work Safety, Athens, Greece.

[8] (1996) IKA social security fund. Statistical Report 96, Athens, Greece.

[9] O. I. Okoye and R. E. Umeh, (2002) Eye health of industrial workers in Southeastern Nigeria. West Afr J Med, 21 (2), 132-137.

[10] F. Cruciani, F. Lucchetta, F. Regine, A. G. Salandri, B. Abdolrahimzadeh, C. Balacco Gabriele, (1997) Work- related accidents of ophthalmologic interest in Italy during 1986-1991. Opthalmologica, 211(4), 215-4.

[11] S. S. Islam, E. J. Doyle, A. Velilla, C. J Martin, (2000) Ducatman AM, Epidemiology of compensable work-related ocular injuries and illnesses: Incidence and risk factors. Journal of Occupational \& Environmental Medicine, 42(6), 575-581.

[12] M. Angelou and P. Theodorakopoulos (1998) The Incidence of opthalmological accidents in the Thriacion Plain industrial zone during the period 1990-1997. Proceedings of the $31^{\text {st }}$ Pan-Hellenic Opthalmological Conference, Chalkidiki, Greece.

[13] M. Angelou, P. Theodorakopoulos, K. Rougas, S. Skouriotis, (2001) Retrospective study of industrial and household ophthalmological accidents in juveniles in the Thriacion Plane area of Attica during the decade 1991-2000. Proceedings of the $34^{\text {th }}$ Pan-Hellenic Ophthalmological Conference, Athens, Greece.

[14] K. Souliotis and J. Kyriopoulos, (2003) Health expenditures in Greece: Measurement problems and policy issues. Applied Health Economics and Health Policy, 2(3).

[15] M. Analytis, (1998) The European parliament on health and work safety. 1989-1994 Reports, Hellenic Institute of Health and Work Safety, Athens, Greece. 